\title{
Bioaugmentation of a historically contaminated soil by polychlorinated biphenyls with Lentinus tigrinus
}

Ermanno Federici ${ }^{1+}$, Mariangela Giubilei ${ }^{2}$, Guglielmo Santi ${ }^{2}$, Giulio Zanaroli ${ }^{3 \dagger}$, Andrea Negroni ${ }^{3}$, Fabio Fava ${ }^{3 \dagger}$, Maurizio Petruccioli ${ }^{2+}$ and Alessandro D'Annibale $2^{2^{*}+}$

\begin{abstract}
Background: Several species belonging to the ecological group of white-rot basidiomycetes are able to bring about the remediation of matrices contaminated by a large variety of anthropic organic pollutants. Among them, polychlorobiphenyls (PCBs) are characterized by a high recalcitrance due to both their low bioavailability and the inability of natural microbial communities to degrade them at significant rates and extents. Objective of this study was to assess the impact of a maize stalk-immobilized Lentinus tigrinus CBS 577.79 inoculant combined with soybean oil (SO), as a possible PCB-mobilizing agent, on the bioremediation and resident microbiota of an actual Aroclor 1260 historically contaminated soil under unsaturated solid-phase conditions.

Results: Best overall PCB depletions (33.6 $\pm 0.3 \%)$ and dechlorination (23.2 $\pm 1.3 \%)$ were found after $60 \mathrm{~d}$ incubation in the absence of $\mathrm{SO}$ where, however, the fungus appeared to exert adverse effects on both the growth of biphenyl- and chlorobenzoate-degrading bacteria and the abundance of genes coding for both biphenyl dioxygenase $(b p h)$ and catechol-2,3-dioxygenase. A significant $(P<0.001)$ linear inverse relationship between depletion yields and degree of chlorination was observed in both augmented and control microcosms in the absence of SO; conversely, this negative correlation was not evident in SO-amended microcosms where the additive inhibited the biodegradation of low chlorinated congeners. The presence of $\mathrm{SO}$, in fact, resulted in lower abundances of both biphenyl-degrading bacteria and bph.

Conclusions: The PCB depletion extents obtained in the presence of L. tigrinus are by far higher than those reported in other remediation studies conducted under unsaturated solid phase conditions on actual site soils historically contaminated by Aroclor 1260. These results suggest that the bioaugmentation strategy with the maize stalk-immobilized mycelium of this species might be promising in the reclamation of PCB-contaminated soils. The addition of SO to matrices contaminated by technical PCB mixtures, such as Aroclor 1242 and Delor 103 and characterized by a large preponderance of low chlorinated congeners, might not be advisable.
\end{abstract}

Keywords: Polychlorinated biphenyls, Lentinus tigrinus, Bioaugmentation, Soybean oil, Degradation, Dechlorination, Biodiversity, Microbial community structure

\section{Background}

The ubiquitous contamination of terrestrial and aquatic ecosystems by polychlorinated biphenyls (PCBs) has become a matter of increasing concern due to their toxicity and ability to accumulate along the food chain

\footnotetext{
* Correspondence: dannib@unitus.it

† Contributed equally

${ }^{2}$ Department for Innovation in Biological, Agro-Food and Forest Systems,

University of Tuscia, Viterbo, Italy

Full list of author information is available at the end of the article
}

[1]. PCBs theoretically encompass as many as 209 different compounds, generally referred to as congeners, with a number of chlorine substitutions in the biphenyl nucleus varying from 1 to 10 . From their first production in the 1930s, until their ultimate ban in the 1990s, the overall PCBs production has been estimated to approximately amount to 1.3 million tons, significant aliquots of which have been released in the environment mainly due to either accidental spills or improper

\section{Ciomed Central}


disposal [1]. The environmental persistence of PCBs is due to their high hydrophobicity and chemical stability and to the inability of natural aquatic and soil biota to perform their mineralization at a considerable rate [2]. While biphenyl and monochlorobiphenyls can serve as growth substrates for several aerobic bacterial species, the degradation of $\mathrm{PCB}$ congeners with more than one chlorine substituent occurs through co-metabolism in which biphenyl exerts the dual role of energy source and inducer of the PCB-degrading enzymes [2,3]. Such biphenyl-induced dioxygenase enzyme system is only able to attack congeners with a number of chlorine substituents varying from 1 to 5 and the effects of chlorination pattern on bacterial PCB degradation have been shown to be due to restrictions on 2,3- or 3,4-dioxygenase attacks [2].

Unlike bacteria, several white-rot basidiomycetes (WRB) have been shown to degrade technical PCB mixtures $[4,5]$ in the absence of biphenyl, the use of which is considered impractical in bioremediation [6]. WRB possess an extracellular radical-based enzyme ligninolytic machinery with low substrate specificity and able to oxidize a wide array of persistent organic contaminants $[7,8]$. Although fungal extracellular phenoloxidases (EPO), such as laccase and Mn-dependent peroxidase, have been found to be unable to oxidize PCB congeners [9], they are able to perform the breakdown of some degradation intermediates such as their hydroxylated derivatives $[10,11]$. Similarly to bacteria, PCB degradation by WRB appears to decrease as the degree of chlorination increases [7,9]. However, any mechanistic interpretation on the effect of the chlorination pattern is prevented by the lack of information concerning the enzymatic basis of the fungal breakdown of these contaminants. The use of WRB in soil requires the addition of lignocellulosic wastes in order to improve their ability to compete with the resident microbiota $[8,12]$. Some of these wastes might be a valuable alternative to biphenyl addition due to their contents in either terpenes or phenylpropanoids which have a stimulatory effect on specialized PCBdegrading bacteria [13]. In this respect, maize stalks might be really valuable $[14,15]$. The reduced PCB bioavailability stemming from their high tendency to become adsorbed to organic matter colloids [16] has been shown to be partially counteracted by the use of synthetic [17] or biogenic $[18,19]$ mobilizing agents (MAs).

Plant oils may be a valuable alternative to conventionally used MAs, due to their cost-effectiveness and ability in enhancing clean-up levels in soils contaminated by persistent organic pollutants [20,21]; to date, however, their use has not been reported in the remediation of PCB-contaminated matrices.

Thus, objective of this study was to assess the impact of a maize stalk-immobilized Lentinus tigrinus CBS
577.79 inoculant combined with soybean oil (SO) on both clean-up and resident microbiota of an actual Aroclor 1260-contaminated soil. To this aim, unsaturated solid-phase conditions were adopted owing to their similarity with those used at the field-scale remediation. On the one hand, the fungus was selected owing to its previously reported ability to degrade PCBs in the technical mixture Delor 106 [4] and their degradation intermediates (i.e., chlorinated benzoic acids) [22]. On the other hand, the above mentioned contaminated soil was chosen since a very limited PCB degradation had been previously therein observed after an aerobic biostimulation treatment in the presence of both biphenyl and randomly methylated- $\beta$-cyclodextrins [19]. Bioaugmented microcosms were compared with homologous incubation controls to highlight the impact of the fungus on: (i) microbial density of cultivable heterotrophic and specialized bacteria (ii) diversity of the indigenous bacteria and fungi, (iii) abundances of functional genes in PCB degradation and (iv) PCB degradation performances in the aged soil. These objectives were pursued by an integrated approach, consisting of a combination of specific chemical, microbiological and molecular methods.

\section{Results and discussion}

Time- and treatment-dependent evolution of fungal biomass and cultivable bacteria

In the incubation control microcosms with and without soybean oil (ICM and ICSOM, respectively), the fungal biomass, indirectly estimated from the soil's ergosterol content, increased with time and the presence of soybean oil (SO) in the latter microcosm appeared to stimulate mycelial growth (Figure 1A). The fungal biomass also increased with time in L. tigrinus microcosm (LtM) and was significantly higher than in non-bioaugmented microcosms. In the L. tigrinus microcosm with soybean oil (LtSOM), instead, the biomass increased 7 -fold within the early $30 \mathrm{~d}$ incubation to remain constant thereafter (Figure 1A). Regardless of the incubation time, fungal biomass in $L t \mathrm{SOM}$ was lower than in $L t \mathrm{M}$.

Although the use of plant oils in mycoremediation has already been reported [20,21], very limited information is currently available on the impact of these additives on mycelial growth at soil moisture contents close to or lower than the water-holding capacity (WHC). In this respect, $\mathrm{SO}$ was found to exert a significant stimulatory action on the growth of several allochthonous fungi in soils spiked with polycyclic aromatic hydrocarbons $[8,23]$.

The lower fungal biomass detected in LtSOM than in $L t \mathrm{M}$ might be ascribed to possible toxic effects exerted by SO-mobilized PCBs towards L. tigrinus. In addition, the significant amount of SO added to soil (i.e., 2.5\%, w/ w) might have resulted in a nutrient imbalance between added carbon and available nutrients thus increasing 


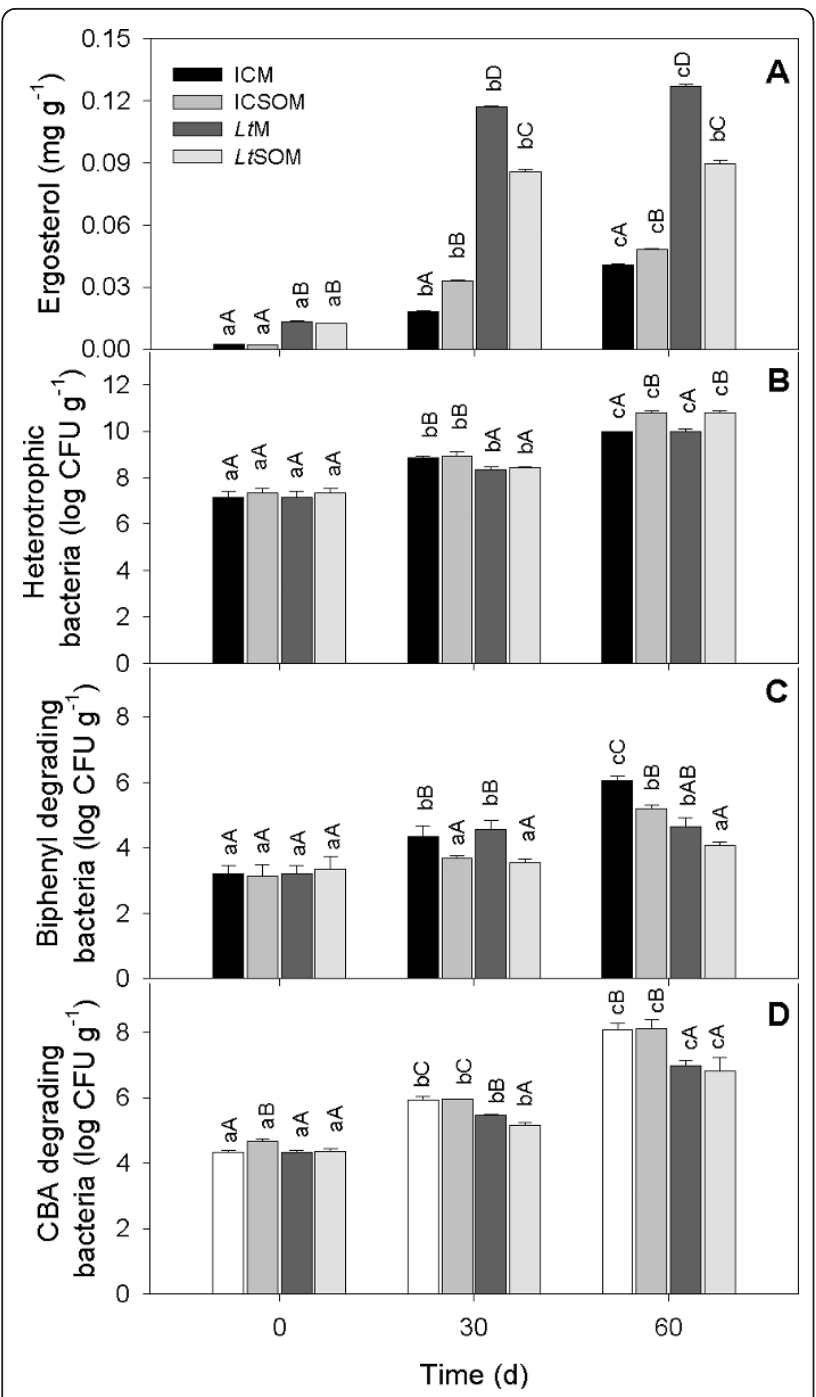

Figure 1 Densities in heterotrophic and specialized bacteria and ergosterol contents in myco-augmented microcosms and respective controls. Changes in concentration of indigenous cultivable aerobic bacteria and in ergosterol content after 0, 30 and $60 \mathrm{~d}$ treatment at $28^{\circ} \mathrm{C}$ in the incubation control and Lentinus tigrinus microcosms in the absence (i.e., ICM and LtM respectively) and in the presence (i.e., ICSOM and LtSOM) of soybean oil (2.5\%, W/W). A, Total aerobic heterotrophic bacteria; B, specialized aerobic bacteria able to growth on biphenyl; $C$, specialized aerobic bacteria able to growth on monochlorobenzoic acids (CBA); D, ergosterol. Data are means \pm standard deviations of 2 replicated experiments. Multiple pair-wise comparisons were performed by the Tukey test ( $P$ $<0.05)$. Same lower case and upper case letters denote absence of statistical significance between time-dependent changes within the same treatment and between treatments at the same time, respectively.

competitive effects between indigenous microbiota and L. tigrinus, as previously observed by Pizzul and collaborators [20].

Regardless of the presence or the absence of SO, $L$. tigrinus showed the ability to efficiently compete with the resident microbiota leading to ergosterol contents in $L t \mathrm{M}$ and $L t \mathrm{SOM}$ 6.5- and 2.6-fold higher, respectively, than in the corresponding incubation controls (i.e., ICM and ICSOM) (Figure 1A). The ability of L. tigrinus to antagonize indigenous microorganisms might be due to its reported ability to produce antimicrobial compounds able to inhibit a wide range of bacteria and fungi $[24,25]$. The inoculum formulation, using milled maize stalks (MMS) as the carrier, might be another determinant for the successful colonization of L. tigrinus. With this regard, several mycoremediation studies showed that lignocellulosic carriers confer to fungi either an initial competitive advantage over resident microbiota [26] or an increased tolerance to inhibitory effects exerted by contaminants [27].

The number of cultivable heterotrophic bacteria appeared to rise with time in all microcosms (Figure 1B). Pair-wise comparisons within the same incubation time of homologous microcosms (i.e., ICM vs. ICSOM and $L t \mathrm{M} v s$. LtSOM) showed that their densities were not affected by the presence of SO after $30 \mathrm{~d}$ incubation and significantly enhanced in the successive harvest (Figure 1B).

A time-dependent growth increase of biphenyl-degrading bacteria (BDB) was only observed in ICM (Figure 1C). In fact, no significant changes in BDB densities were observed over time in $L t \mathrm{SOM}$ while a delayed rise was evident in both $L t \mathrm{M}$ and ICSOM (Figure 1C). Pairwise comparisons within the same incubation times highlighted a depressive effect on BDB densities due to the presence of SO. With regard to the effect of the added fungus, significant differences between augmented vs. non-inoculated controls were only found at $60 \mathrm{~d}$ incubation where the former microcosms exhibited lower BDB concentrations. The concentrations of CBAdegrading bacteria, instead, tended to increase over time with no exceptions. However, in both 30- and 60-d-old microcosms, the densities of CBA degraders in LtM and $L t$-SOM were lower than in ICM and ICSOM.

\section{Evolution of bacterial and fungal community profiles and diversity}

In order to gain more insights into the impact of both $L$. tigrinus and SO on the resident microbiota, a cultivation independent approach based on DGGE analysis of both $16 \mathrm{~S}$ and $18 \mathrm{~S}$ rRNA genes was employed taking into account that cultivable microbes represent only a minor fraction of the overall microbial community. DGGE analysis of $16 \mathrm{~S}$ rRNA gene showed a time-dependent increase in both richness $(S)$ and Shannon Weaver index $(H)$ in all microcosms with the notable exception of the 30-d-old ICSOM where no significant changes in these parameters were found with respect to the zero time-point. The presence of L. tigrinus appeared to 
enhance the bacterial diversity as inferred by comparing bioaugmented microcosms with respective incubation controls. These results are in agreement with a previous mycoremediation study where the same fungal strain had been reported to improve the bacterial diversity [28]. Figure 2B shows the presence of two main clusters with the former including all microcosms at start. Within the latter cluster, bioaugmented microcosms segregated from non-inoculated ones with the exception of 30-d-old LtM.

DGGE analysis of $18 \mathrm{~S}$ rRNA gene showed a poor biodiversity of the fungal biota at start with $S$ and $H$ values ranging from 5 to 11 and 0.43 to 0.76 , respectively (Figure $3 \mathrm{~A}$ ). However, regardless of the microcosm type, both parameters appeared to increase over time. As opposed to bacteria, an increase in fungal diversity was already observed at the first harvest even in the presence of SO. Figure 3B shows the presence of two main clusters, the former including all the microcosms at start and the latter the remaining harvests. Within the latter one, bioaugmented microcosms displayed a low level of similarity (i.e., 0.53) with the non-inoculated ones. Low levels of biodiversity of the mycobiota, a common pattern in historically contaminated soils [29], had been also observed by Tigini et al. [30] in another Aroclor 1260 contaminated soil and ascribed to the selective pressure on the resident fungal community due to the concomitant presence of PCBs and heavy metals. As opposed to Tigini et al. [30], who observed lower fungal loads and species number after $120 \mathrm{~d}$ of either biostimulation or bioaugmentation of that soil, both fungal density and biodiversity increased regardless of the presence or the absence of the exogenous fungus. However, those findings were limited to cultivable mycobiota [30].

\section{Functional aspects of resident microbial community in PCB-contaminated microcosms}

In all microcosms, dehydrogenase activity appeared to increase with the incubation time (Figure 4A). However, at both harvests, this activity was strikingly higher in bioaugmented microcosms than in non-inoculated ones; in the former and in the latter microcosms, the presence of SO either increased or did not affect dehydrogenase activity, respectively (Figure 4A). Dehydrogenase activity has been shown to be a valuable and robust indicator of detoxification in contaminated soils [31]. However, in this study, it was not significantly correlated with residual PCB contents in all the microcosms $\left(\mathrm{R}^{2}=0.184 ; P\right.$

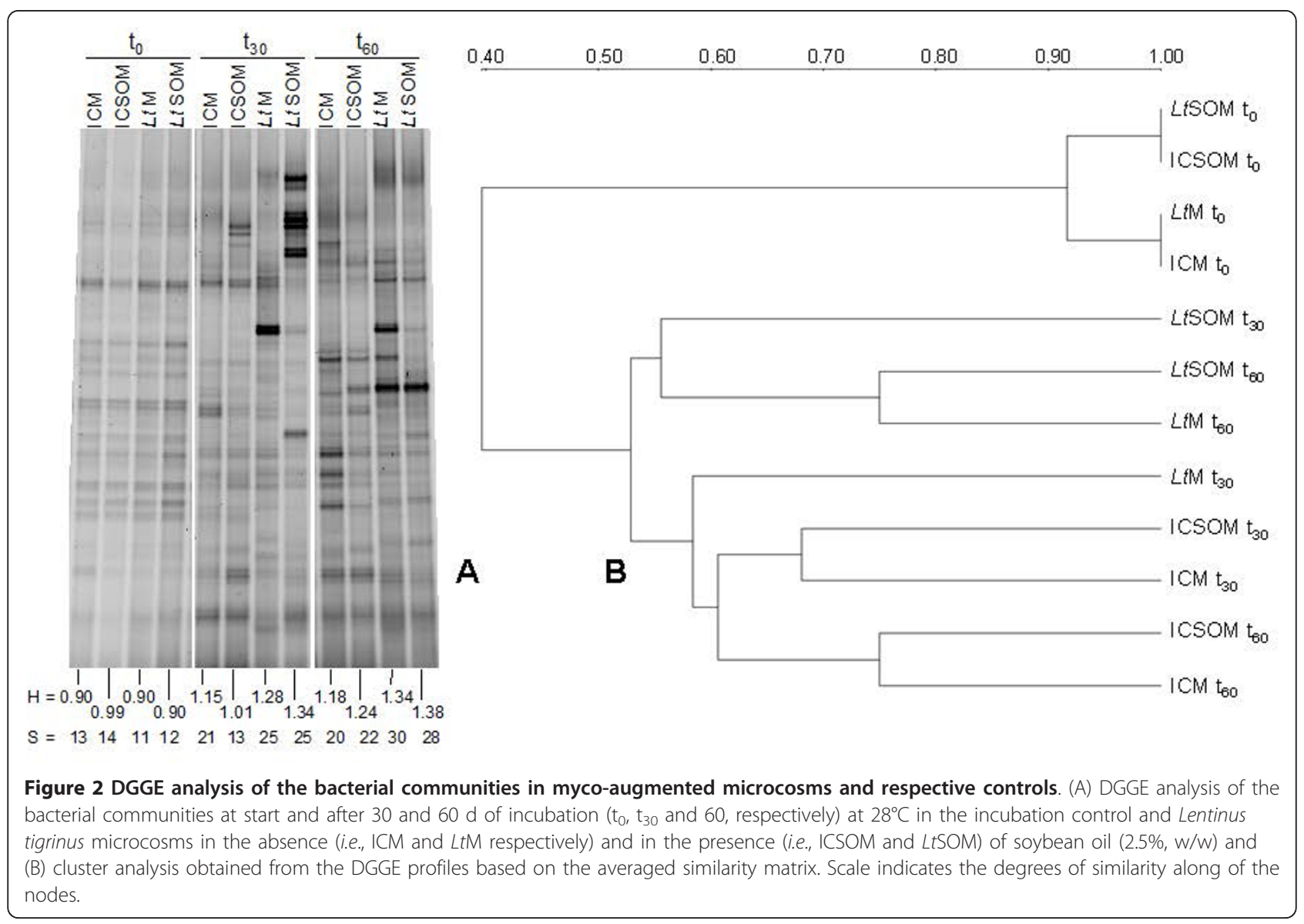




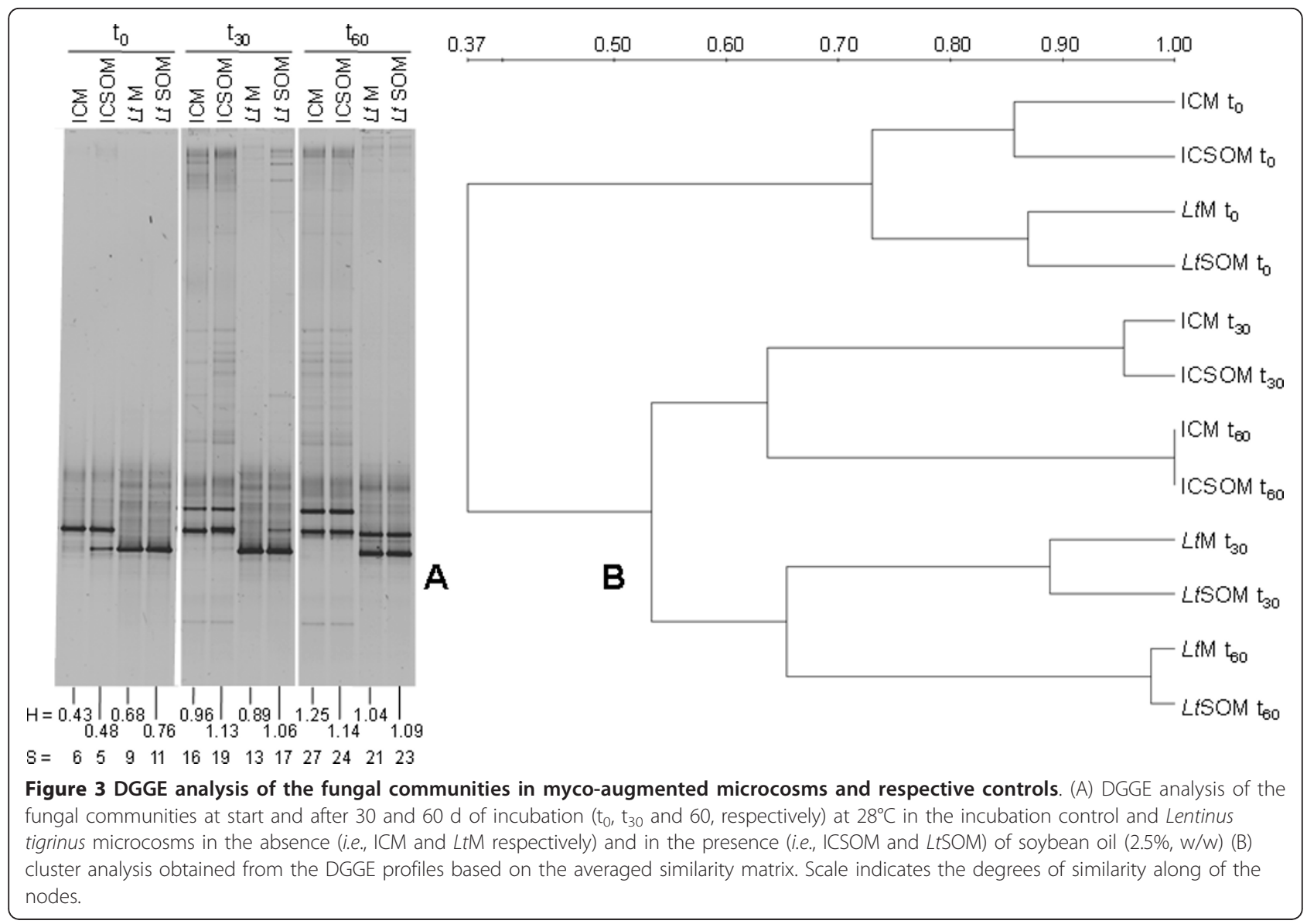

$=0.29$ ) although its time-dependent rise denoted an increased microbial activity.

All the microcosms shared the presence of MMS mainly composed by cell wall polysaccharides and lignin [32]. Thus, the time courses of extracellular glycosylhydrolase (EGH) and extracellular phenoloxidase (EPO) activities were determined as additional indices of metabolic activity in the investigated microcosms. In nonbioaugmented microcosms, despite the observed timedependent increase in fungal biomass, EGH activities did not significantly vary over time with the only exception of endo-1,4-xylanase in the ICSOM; in the same microcosms, EPO activities were not detected (Figure 4C).

In $L t \mathrm{M}$, conversely, all the EGH and EPO activities exhibited similar trends characterized by an initial increase after $30 \mathrm{~d}$ followed by a significant decline in the subsequent harvest. The presence of SO in LtSOM appeared to mitigate the aforementioned activity decline of endo- $\beta-1,4$-glucanase, endo- $\beta-1,4$-xylanase and cellobiohydrolase in the 30-60 d time range (Figures 4B, C and $4 \mathrm{D}$, respectively); the same trend was also observed for both laccase and $\mathrm{Mn}$-dependent peroxidase activities (Figures 4E and 4F, respectively).
The abundances of the 16S rRNA gene in ICM and ICSOM increased approx. 21- and 24-fold, respectively, with respect to the zero time point after $60 \mathrm{~d}$ incubation (Figure 5A). Albeit to a lesser extent, such an increase was also observed in bioaugmented microcosms (i.e., approx. 2.8 and 3.2-fold in $L t \mathrm{M}$ and $L t \mathrm{SOM}$, respectively).

The degradation of low chlorinated PCBs by aerobic bacteria is often initiated by a biphenyl 2,3-dioxygenase (bph), belonging to the family of Rieske non-heme iron oxygenases, which catalyzes the incorporation of molecular oxygen at the 2,3 position of the non-chlorinated or lesser chlorinated ring of PCB to form cis-dihydrodiol compounds $[2,6]$. The time course of biphenyl dioxygenase (bph) gene abundances in IC and ICSOM showed a marked decline after $30 \mathrm{~d}$ followed by a slight increase at $60 \mathrm{~d}$ (2.8- and 1.3-fold, respectively). In bioaugmented microcosms, $b p h$ abundances, instead, were lower than in the same microcosms at start regardless of the incubation time (Figure 5B) thus suggesting a competitive activity exerted by the fungus and confirming the BDB enumeration results (Figure 1C).

The aerobic conversion of chlorobenzoates, common PCB degradation intermediates, usually proceeds via the 


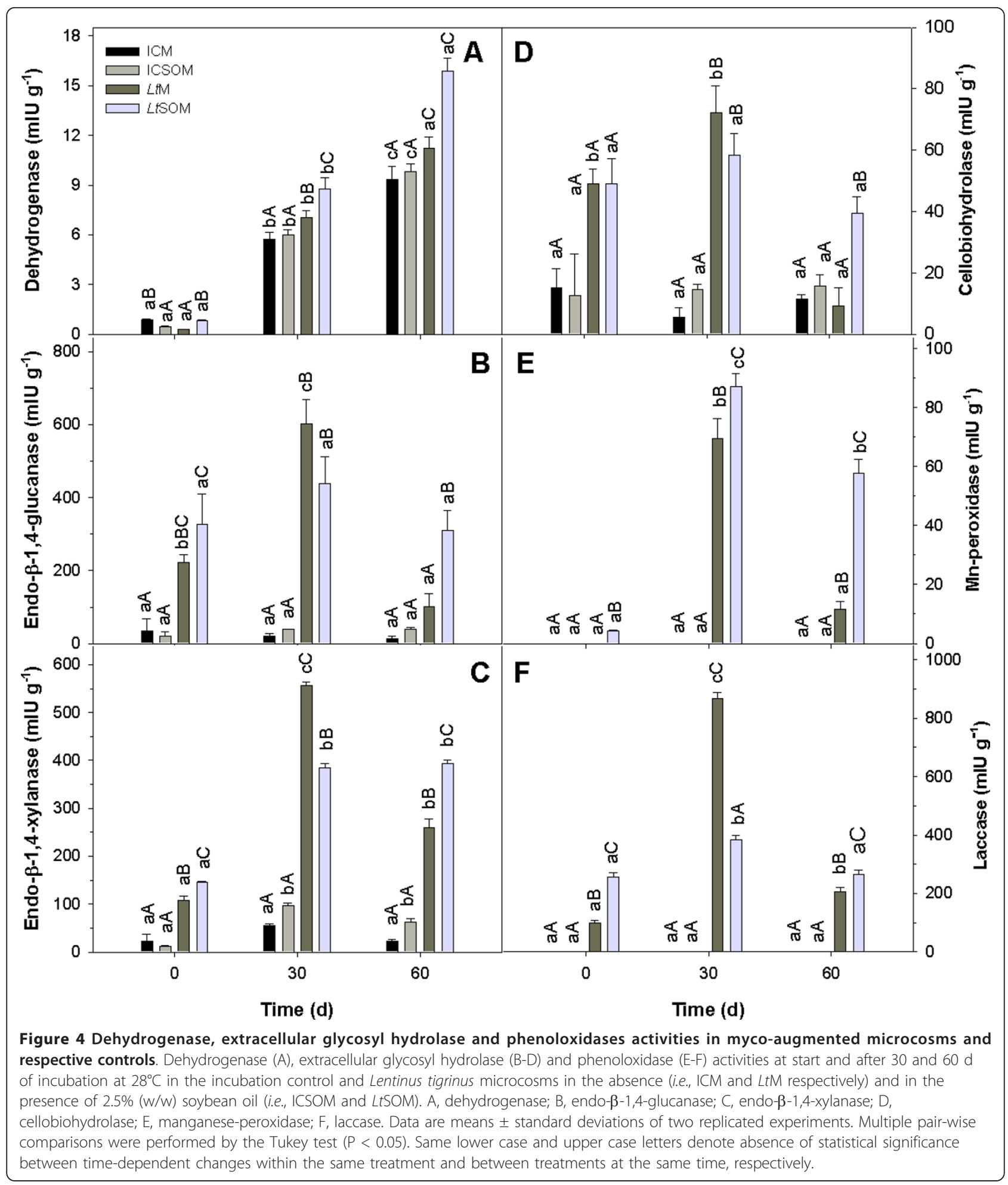

formation of chlorinated catechols, which, in turn, undergo either ortho- or meta-cleavage [2,3]. The latter ring fission mechanism is brought about by 2,3 -catechol-dioxygenase yielding hydroxy-substituted chloromuconic semialdehydes [2]. With regard to the abundance of the 2,3-catechol-dioxygenase (C230) gene, pertaining to the lower $\mathrm{PCB}$ degradation pathway, a time-dependent increase was found for all microcosms although the highest folds were displayed by the nonbioaugmented ones (46- and 61-fold for ICM and 


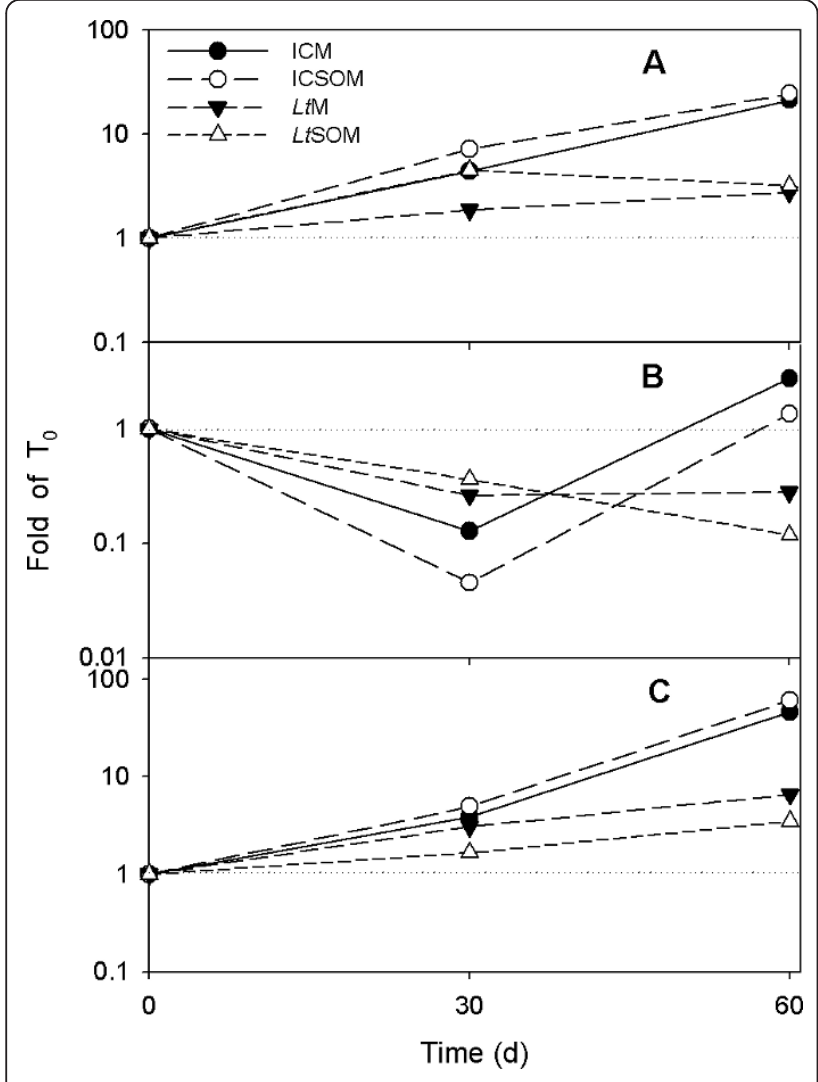

Figure 5 q-PCR analyses of $16 S$ rRNA, bph and C230 abundances in myco-augmented microcosms and respective controls. Semi-logarithmic plots of time dependent changes in the relative amount of 165 rRNA (A) bph (B), C230 (C) qPCR-amplified genes in the incubation control and Lentinus tigrinus microcosms in the absence (i.e., ICM and LtM respectively) and in the presence of $2.5 \%(\mathrm{w} / \mathrm{w})$ soybean oil (i.e., ICSOM and LtSOM). Data are expressed as fold with respect to the relative zero time-point (please, see Materials and Methods).

ICSOM, respectively) (Figure 5C). The presence of SO appeared to exert an opposite impact on $\mathrm{C} 230$ gene, the abundance of which was positively and negatively affected in the incubation controls and the augmented microcosms, respectively (Figure $5 \mathrm{C}$ ).

\section{PCB degradation}

Table 1 shows both identities and respective initial concentrations of PCB congeners in ICM and ICSOM, the overall contents of which were higher than $700 \mathrm{mg} \mathrm{kg}^{-1}$. Three- up to hepta-chlorinated CBs encompassed the large majority of contaminants therein detected and, among them, the largest relative abundances were observed for tetra- and hexa-CBs (about 26 and 23\%, respectively). PCB recoveries preliminarily investigated both in the absence and in the presence of MMS, which was employed in all microcosms, did not significantly differ. With few exceptions, the highest percent depletions of di-, tri-, tetra- and penta-CBs were observed in $L t \mathrm{M}$ that also exhibited better removal performances towards hexa- hepta and octa-CBs than its corresponding incubation control (i.e., ICM). Despite these differences, a highly significant negative correlation between contaminant removal and degree of chlorination was found in both ICM and $L t \mathrm{M}\left(\mathrm{R}^{2}\right.$ adj equal to 0.968 and 0.981 , respectively, $P<0.001$ ). In this respect, it is known that lipophilicity and molar water solubility of PCBs tend to increase and decrease, respectively, as the degree of halogenation increases [33] and, thus, high chlorinated congeners show a low susceptibility to biodegradation $[2,3]$.

The aforementioned relationship between percent depletion of homologues and respective degree of halogenation was significantly affected by the presence of soybean oil. In both ICSOM and LtSOM, in fact, depletions increased as the number of chlorine substituents increased from 2 to 4 and then tended to decrease for higher chlorinated homologues (Figure 6). However, pair-wise comparisons between homologous microcosms (i.e, ICM vs. ICSOM and $L t \mathrm{M} v s$. LtSOM, respectively) showed that the depletions of low chlorinated congeners were significantly depressed by the presence of SO. For instance, the observed depletions in ICM and $L t \mathrm{M}$ of diCBs (47.3 and 53.3\%, respectively) and tri-CBs (39.7 and $45.8 \%$, respectively) drastically dropped in ICSOM and $L t \mathrm{SOM}$ to 22.3 and $23.8 \%$, respectively, and to 25.0 and $27.7 \%$, respectively, for the former and the latter homologues. Albeit to a lesser extent, the same trend was observed for tetra- and penta-CBs. Conversely, the presence of SO differentially affected the depletions of hexa- up to octa-CBs in bioaugmented and incubation control microcosms with respect to those observed in their respective non-amended ones. In fact, high chlorinated homologues in $L t \mathrm{M}$ and $L t \mathrm{SOM}$ were depleted to the same extent; conversely, ICM exhibited lower removal performances than ICSOM.

The possible occurrence of a variety of interfering effects (i.e., volatilization, sorption on either soil colloids or microbial biomass) does not necessarily ensure that congener losses determined by gas-chromatography with electron-capture detection be due to actual biodegradation. With this regard, the impact of biosorption phenomena on apparent PCB degradation was not found to be adequately quantified by the use of heat-killed controls [9]. Thus, since chloride removal is known to occur throughout advanced PCB breakdown steps, the release of chloride was used in the present study as a valuable indicator of their degradation [2]. On the basis of the theoretical content of PCB-bound chloride, calculated according to Brinkman and de Kok [34], and on the initial inorganic chloride contents in the microcosms under study, it was possible to assess that a substantial 
Table 1 Initial PCB congeners concentrations and percent degradation in myco-augmented and control microcosms

\begin{tabular}{|c|c|c|c|c|c|c|}
\hline \multirow[t]{2}{*}{ Target soil PCBs (congener) } & \multicolumn{2}{|c|}{ Initial concentration ( $\mathrm{mg} \mathrm{kg}^{-1}$ soil) } & \multicolumn{4}{|c|}{ Average depletion (\%)* } \\
\hline & Soil as such & Soil with SO & ICM & ICSOM & LtM & LtSOM \\
\hline $2,6-/ 2,2^{\prime}-C B$ & $1.35 \pm 0.004$ & $1.05 \pm 0.003$ & $85.6 c$ & $0.0 \mathrm{a}$ & $44.6 b$ & $0.0 \mathrm{a}$ \\
\hline $2,4-/ 2,5-C B$ & $0.09 \pm 0.001$ & $0.12 \pm 0.003$ & $94.3 b$ & $16.2 \mathrm{a}$ & $37.2 \mathrm{a}$ & $21.7 a$ \\
\hline $2,3^{\prime}-\mathrm{CB}$ & $0.43 \pm 0.001$ & $0.35 \pm 0.003$ & $0.0 \mathrm{a}$ & $36.1 \mathrm{~b}$ & $89.1 \mathrm{c}$ & $33.7 b$ \\
\hline $2,4^{\prime}-/ 2,3-C B$ & $0.11 \pm 0.001$ & $0.08 \pm 0.001$ & $100 \mathrm{~b}$ & $39.5 \mathrm{a}$ & $82.7 b$ & 47.3a \\
\hline $2,2^{\prime}, 6-\mathrm{CB}$ & $2.73 \pm 0.000$ & $2.62 \pm 0.004$ & $37.9 b$ & $23.2 \mathrm{a}$ & $59.4 c$ & $23.9 a$ \\
\hline $2,2^{\prime}, 5-/ 2,2^{\prime}, 4-/ 4,4^{\prime}-C B$ & $39.33 \pm 0.053$ & $36.15 \pm 0.097$ & $44.2 b$ & $23.9 a$ & $52.9 \mathrm{c}$ & $25.4 a$ \\
\hline $2,3,6-/ 2,3,6-C B$ & $3.07 \pm 0.000$ & $2.87 \pm 0.009$ & $42.7 b$ & $24.8 \mathrm{a}$ & $50.8 \mathrm{c}$ & $27.0 \mathrm{a}$ \\
\hline $2,2^{\prime}, 3-/ 2,4^{\prime}, 6-C B$ & $16.14 \pm 0.018$ & $14.99 \pm 0.045$ & $41.0 \mathrm{~b}$ & $25.3 a$ & $50.1 \mathrm{c}$ & $27.3 a$ \\
\hline $2^{\prime}, 3,5-\mathrm{CB}$ & $0.23 \pm 0.001$ & $0.21 \pm 0.002$ & $48.0 b$ & $29.1 \mathrm{a}$ & $45.6 b$ & $31.8 \mathrm{a}$ \\
\hline $2,4,5-C B$ & $0.21 \pm 0.001$ & $0.18 \pm 0.000$ & $48.7 c$ & $26.5 a$ & $51.9 d$ & $29.5 b$ \\
\hline $2,3^{\prime}, 5-C B$ & $7.29 \pm 0.007$ & $6.66 \pm 0.019$ & $39.2 \mathrm{C}$ & $25.2 \mathrm{a}$ & $43.1 \mathrm{~d}$ & $28.9 b$ \\
\hline $2,3^{\prime}, 4-C B$ & $2.28 \pm 0.007$ & $2.04 \pm 0.004$ & $38.9 c$ & $23.6 a$ & $43.3 \mathrm{~d}$ & $26.0 b$ \\
\hline $2,4^{\prime}, 5-/ 2,4,4^{\prime}-C B$ & $60.03 \pm 0.111$ & $55.17 \pm 0.157$ & $37.7 \mathrm{c}$ & $25.8 \mathrm{a}$ & $40.8 \mathrm{~d}$ & $29.1 b$ \\
\hline $2,3,3^{\prime}-12^{\prime}, 3,4-/ 2,2^{\prime}, 5,6^{\prime}-\mathrm{CB}$ & $7.45 \pm 0.009$ & $6.77 \pm 0.019$ & $36.7 c$ & $23.7 a$ & $42.9 d$ & $26.7 b$ \\
\hline $2,2^{\prime}, 4,6^{\prime}-12,3,4^{\prime}-\mathrm{CB}$ & $27.83 \pm 0.041$ & $25.60 \pm 0.070$ & $34.9 c$ & $26.1 \mathrm{a}$ & $41.6 \mathrm{~d}$ & $29.3 b$ \\
\hline $2,2^{\prime}, 3,6-C B$ & $6.57 \pm 0.008$ & $6.15 \pm 0.017$ & $37.6 b$ & $27.1 \mathrm{a}$ & $47.2 \mathrm{C}$ & $29.8 a$ \\
\hline $2,2^{\prime}, 3,6^{\prime}-C B$ & $3.09 \pm 0.001$ & $2.90 \pm 0.009$ & $35.4 b$ & $30.5 \mathrm{a}$ & $49.9 c$ & $31.5 \mathrm{a}$ \\
\hline $2,2^{\prime}, 5,5^{\prime}-\mathrm{CB}$ & $26.04 \pm 0.035$ & $24.31 \pm 0.063$ & $35.9 c$ & $26.3 a$ & $39.8 d$ & $29.9 b$ \\
\hline $2,2^{\prime}, 4,5^{\prime}-C B$ & $18.55 \pm 0.022$ & $17.24 \pm 0.065$ & $36.0 c$ & $26.6 a$ & $40.0 \mathrm{~d}$ & $30.1 b$ \\
\hline $2,2^{\prime}, 4,4^{\prime}-12,2^{\prime}, 4,5-/ 2,4,4^{\prime}, 6-C B$ & $9.55 \pm 0.018$ & $8.83 \pm 0.010$ & $36.5 c$ & $26.8 \mathrm{a}$ & $42.8 \mathrm{~d}$ & $30.3 b$ \\
\hline $3,3^{\prime}, 4-C B$ & $0.85 \pm 0.002$ & $0.79 \pm 0.006$ & $30.7 a b$ & $27.4 a$ & $36.8 b$ & $32.8 b$ \\
\hline $2,2^{\prime}, 3,5^{\prime}-\mathrm{CB}$ & $18.83 \pm 0.039$ & $17.44 \pm 0.034$ & $34.2 \mathrm{C}$ & $25.3 \mathrm{a}$ & $38.3 d$ & $29.2 b$ \\
\hline $3,4,4^{\prime}-/ 2,3,3^{\prime}, 6-/ 2,2^{\prime}, 3,4^{\prime}-C B$ & $10.38 \pm 0.013$ & $9.54 \pm 0.032$ & $31.7 c$ & $26.9 a$ & $38.2 d$ & $30.1 b$ \\
\hline $2,2^{\prime}, 3,4-/ 2,3,4^{\prime}, 6-C B$ & $20.96 \pm 0.037$ & $19.39 \pm 0.055$ & $33.2 \mathrm{c}$ & $27.9 a$ & $39.8 \mathrm{~d}$ & $31.9 b$ \\
\hline $2,2^{\prime}, 3,3^{\prime}-\mathrm{CB}$ & $6.01 \pm 0.006$ & $5.56 \pm 0.017$ & $31.1 \mathrm{c}$ & $26.6 a$ & $40.6 \mathrm{~d}$ & $29.8 b$ \\
\hline $2,3^{\prime}, 4,5-C B$ & $2.45 \pm 0.001$ & $2.39 \pm 0.008$ & $28.9 a$ & $28.6 a$ & $35.5 c$ & $32.6 b$ \\
\hline $2,3,4^{\prime}, 5-C B$ & $1.23 \pm 0.001$ & $1.11 \pm 0.003$ & $28.1 b$ & $26.0 \mathrm{a}$ & $29.6 b$ & $28.9 b$ \\
\hline $2,4,4^{\prime}, 5-C B$ & $12.83 \pm 0.011$ & $12.07 \pm 0.045$ & $30.2 b$ & $27.6 a$ & $33.3 \mathrm{~d}$ & $31.0 \mathrm{c}$ \\
\hline $2,3^{\prime}, 4^{\prime}, 5-C B$ & $21.95 \pm 0.030$ & $20.60 \pm 0.071$ & $29.6 b$ & $27.5 \mathrm{a}$ & $34.1 d$ & $30.7 c$ \\
\hline $2,2^{\prime}, 3,5^{\prime}, 6-C B$ & $25.58 \pm 0.049$ & $24.07 \pm 0.070$ & $28.2 \mathrm{a}$ & $25.4 b$ & $33.1 \mathrm{c}$ & $28.0 \mathrm{a}$ \\
\hline $2,2^{\prime}, 3,4^{\prime}, 6-C B$ & $1.20 \pm 0.001$ & $1.15 \pm 0.003$ & $30.5 \mathrm{a}$ & $31.0 \mathrm{a}$ & $32.0 \mathrm{a}$ & $32.4 a b$ \\
\hline $2,3,4,4^{\prime}-12,3,33^{\prime}, 4^{\prime}-\mathrm{CB}$ & $18.78 \pm 0.032$ & $17.44 \pm 0.051$ & $28.3 a$ & $27.4 a$ & $34.2 \mathrm{C}$ & $30.1 b$ \\
\hline $2,2^{\prime}, 3,5,5^{\prime}-\mathrm{CB}$ & $4.42 \pm 0.005$ & $4.25 \pm 0.022$ & $27.0 \mathrm{a}$ & $25.5 \mathrm{a}$ & $30.6 c$ & $28.6 b$ \\
\hline $2,2^{\prime}, 3,3^{\prime}, 6-C B$ & $8.47 \pm 0.032$ & $7.92 \pm 0.022$ & $31.0 \mathrm{~b}$ & $28.0 \mathrm{a}$ & $36.9 c$ & $30.3 b$ \\
\hline $2,2^{\prime}, 3,4^{\prime}, 5 / 2,2^{\prime}, 4,5,5^{\prime}-\mathrm{CB}$ & $30.81 \pm 0.052$ & $29.22 \pm 0.040$ & $25.2 \mathrm{a}$ & $24.6 a$ & $30.6 c$ & $26.9 b$ \\
\hline $2,2^{\prime}, 4,4^{\prime}, 5-C B$ & $7.49 \pm 0.013$ & $7.34 \pm 0.004$ & $28.6 a$ & $30.0 b$ & $32.2 \mathrm{c}$ & $32.1 \mathrm{c}$ \\
\hline $2,3^{\prime}, 4,4^{\prime}, 6-C B$ & $0.33 \pm 0.002$ & $0.23 \pm 0.184$ & $28.1 \mathrm{~b}$ & $0.1 \mathrm{a}$ & $0.3 a$ & $0.0 a$ \\
\hline $2,2^{\prime}, 3,3^{\prime}, 5-C B$ & $1.29 \pm 0.016$ & $1.36 \pm 0.006$ & $28.5 b$ & $29.0 \mathrm{~b}$ & $16.2 \mathrm{a}$ & $32.0 \mathrm{c}$ \\
\hline $2,2^{\prime}, 3^{\prime}, 4,5-C B$ & $6.77 \pm 0.002$ & $6.44 \pm 0.008$ & $28.7 b$ & $25.2 \mathrm{a}$ & $31.2 \mathrm{c}$ & $28.9 b$ \\
\hline $2,2^{\prime}, 3,4,5^{\prime} / 2,3,4,4^{\prime}, 6-C B$ & $12.10 \pm 0.008$ & $11.40 \pm 0.017$ & $27.2 \mathrm{a}$ & $27.0 \mathrm{a}$ & $31.7 \mathrm{c}$ & $29.8 b$ \\
\hline $2,2^{\prime}, 3,4,4^{\prime}-\mathrm{CB}$ & $3.09 \pm 0.002$ & $3.06 \pm 0.052$ & $25.7 a$ & $30.9 b$ & $29.8 b$ & $37.3 c$ \\
\hline $2,2^{\prime}, 3,3^{\prime}, 6,6^{\prime}-C B$ & $8.43 \pm 0.017$ & $8.01 \pm 0.042$ & $23.5 \mathrm{a}$ & $22.3 a$ & $28.3 b$ & $24.4 a$ \\
\hline $2,3,3^{\prime}, 4^{\prime}, 6-C B$ & $19.87 \pm 0.010$ & $18.75 \pm 0.010$ & $25.6 a$ & $25.7 a$ & $30.5 c$ & $27.9 b$ \\
\hline $2,2^{\prime}, 3,5,5^{\prime}, 6-C B$ & $11.81 \pm 0.008$ & $11.30 \pm 0.023$ & $21.2 \mathrm{a}$ & $22.1 \mathrm{a}$ & $26.4 c$ & $23.9 b$ \\
\hline $2,2^{\prime}, 3,3^{\prime}, 5,6^{\prime}-\mathrm{CB}$ & $8.85 \pm 0.008$ & $8.47 \pm 0.016$ & $21.3 a$ & $22.6 a$ & $25.1 b$ & $24.2 b$ \\
\hline $2,3,3^{\prime}, 4^{\prime}, 5-C B$ & $0.91 \pm 0.000$ & $0.91 \pm 0.009$ & $26.3 a$ & $26.3 a$ & $54.0 \mathrm{~b}$ & $31.2 b$ \\
\hline $2,2^{\prime}, 3,4^{\prime}, 5^{\prime}, 6 / 2,3^{\prime}, 4,4^{\prime}, 5-C B$ & $34.83 \pm 0.024$ & $33.30 \pm 0.067$ & $22.0 \mathrm{a}$ & $23.5 b$ & $27.2 d$ & $25.3 c$ \\
\hline $2,2^{\prime}, 3,3^{\prime}, 5,6-\mathrm{CB}$ & $2.94 \pm 0.007$ & $2.79 \pm 0.006$ & $22.5 \mathrm{a}$ & $23.4 \mathrm{a}$ & $28.2 \mathrm{C}$ & $25.2 b$ \\
\hline $2,2^{\prime}, 3,3^{\prime}, 4,6 / 2^{\prime}, 3,3^{\prime}, 4,5-C B$ & $2.60 \pm 0.002$ & $2.51 \pm 0.007$ & $21.7 a$ & $24.2 b$ & $29.1 d$ & $26.8 \mathrm{c}$ \\
\hline $2,2^{\prime}, 3,4^{\prime}, 5,5^{\prime}-C B$ & $5.51 \pm 0.005$ & $5.38 \pm 0.011$ & $20.1 \mathrm{a}$ & $24.3 b$ & $26.7 c$ & $26.1 c$ \\
\hline
\end{tabular}


Table 1 Initial PCB congeners concentrations and percent degradation in myco-augmented and control microcosms (Continued)

\begin{tabular}{|c|c|c|c|c|c|c|}
\hline $2,2^{\prime}, 3,3^{\prime}, 4,6^{\prime} / 2,2^{\prime}, 4,4^{\prime}, 5,5^{\prime} / 2,3,3^{\prime}, 4,4^{\prime}-\mathrm{CB}$ & $60.87 \pm 0.069$ & $58.57 \pm 0.145$ & $20.3 a$ & $23.4 b$ & $26.6 c$ & $25.1 \mathrm{c}$ \\
\hline $2,2^{\prime}, 3,4,5,5^{\prime} / 2,2^{\prime}, 3,3^{\prime}, 5,6,6^{\prime}-\mathrm{CB}$ & $13.51 \pm 0.019$ & $12.99 \pm 0.033$ & $18.8 \mathrm{a}$ & $21.6 b$ & $24.7 c$ & $23.3 c$ \\
\hline $2,2^{\prime}, 3,3^{\prime}, 4,5^{\prime}+2,2^{\prime}, 3,3^{\prime}, 4,6,6^{\prime} / 2,2^{\prime}, 3,4,4^{\prime}, 5-C B$ & $3.92 \pm 0.007$ & $3.79 \pm 0.012$ & $18.4 a$ & $21.6 b$ & $24.9 c$ & $23.4 c$ \\
\hline $2,3,3^{\prime}, 4,5,6 / 2,2^{\prime}, 3,4,4^{\prime}, 5^{\prime} / 2,3,3^{\prime}, 4,4^{\prime}, 6-C B$ & $34.54 \pm 0.088$ & $33.22 \pm 0.137$ & $20.6 \mathrm{a}$ & $23.9 \mathrm{~b}$ & $26.8 \mathrm{c}$ & $25.6 c$ \\
\hline $2,2^{\prime}, 3,3^{\prime}, 4,5 / 2,2^{\prime}, 3,3^{\prime}, 5,5^{\prime}, 6-C B$ & $6.67 \pm 0.002$ & $6.48 \pm 0.009$ & $13.2 \mathrm{a}$ & $17.9 \mathrm{~b}$ & $20.9 d$ & $19.3 c$ \\
\hline $2,2^{\prime}, 3,3^{\prime}, 4,5^{\prime}, 6+2,2^{\prime}, 3,4^{\prime}, 5,5^{\prime}, 6-C B$ & $10.52 \pm 0.020$ & $10.26 \pm 0.036$ & $15.4 a$ & $19.9 b$ & $22.2 \mathrm{~b}$ & $21.3 b$ \\
\hline $2,2^{\prime}, 3,3^{\prime}, 4^{\prime}, 6,6^{\prime}-\mathrm{CB}$ & $4.89 \pm 0.009$ & $4.76 \pm 0.016$ & $16.8 \mathrm{a}$ & $21.1 b$ & $20.4 c$ & $22.6 c$ \\
\hline $2,2^{\prime}, 3,4,4^{\prime}, 5^{\prime}, 6+2,2^{\prime}, 3,3^{\prime}, 4^{\prime}, 4^{\prime}+2,3^{\prime}, 4,4^{\prime}, 5,5^{\prime}-\mathrm{CB}$ & $9.87 \pm 0.012$ & $9.54 \pm 0.040$ & $20.6 a$ & $24.5 b$ & $27.0 \mathrm{c}$ & $26.5 c$ \\
\hline $2,2^{\prime}, 3,4,5,5^{\prime}, 6-C B$ & $3.15 \pm 0.002$ & $3.08 \pm 0.011$ & 14.8a & $19.6 b$ & $21.0 \mathrm{~b}$ & $21.2 b$ \\
\hline $2,2^{\prime}, 3,3^{\prime}, 4,5,6^{\prime}-\mathrm{CB}$ & $10.35 \pm 0.021$ & $10.06 \pm 0.027$ & $16.0 \mathrm{a}$ & $20.4 b$ & $22.7 b$ & $21.8 \mathrm{~b}$ \\
\hline $2,2^{\prime}, 3,3^{\prime}, 4^{\prime}, 5,6-\mathrm{CB}$ & $5.92 \pm 0.012$ & $5.76 \pm 0.019$ & $16.0 \mathrm{a}$ & $20.7 b$ & $22.8 d$ & $22.1 \mathrm{c}$ \\
\hline $2,2^{\prime}, 3,3^{\prime}, 5,5^{\prime}, 6,6^{\prime} / 2,2^{\prime}, 3,33^{\prime}, 4,4^{\prime}, 6 / 2,3,3^{\prime}, 4,4^{\prime}, 5-C B$ & $10.61 \pm 0.014$ & $10.70 \pm 0.040$ & $16.0 \mathrm{a}$ & $23.2 \mathrm{C}$ & $22.0 \mathrm{~b}$ & $24.9 d$ \\
\hline $2,2^{\prime}, 3,3^{\prime}, 5,5^{\prime}, 6,6^{\prime} / 2,3,3^{\prime}, 4,4^{\prime}, 5^{\prime} / 2,2^{\prime}, 3,3^{\prime}, 4,5^{\prime}, 6,6^{\prime}-C B$ & $3.73 \pm 0.012$ & $3.63 \pm 0.016$ & $12.1 \mathrm{a}$ & $17.6 b$ & $20.4 d$ & $19.2 \mathrm{C}$ \\
\hline $2,2^{\prime}, 3,3^{\prime}, 4,5,5^{\prime}+2,2^{\prime}, 3,3^{\prime}, 4,4^{\prime}, 6,6^{\prime}-\mathrm{CB}$ & $2.30 \pm 0.003$ & $2.08 \pm 0.012$ & $20.1 \mathrm{a}$ & $19.4 \mathrm{a}$ & $27.6 \mathrm{C}$ & $21.0 \mathrm{~b}$ \\
\hline $2,2^{\prime}, 3,4,4^{\prime}, 5,5^{\prime}+2,3,3^{\prime}, 4^{\prime}, 5,5^{\prime}, 6-C B$ & $22.51 \pm 0.043$ & $22.07 \pm 0.075$ & $15.9 \mathrm{a}$ & $21.4 b$ & $23.3 \mathrm{c}$ & $23.0 \mathrm{c}$ \\
\hline $2,3,3^{\prime}, 4,4^{\prime}, 5^{\prime}, 6-C B$ & $0.82 \pm 0.006$ & $0.84 \pm 0.009$ & $15.2 \mathrm{a}$ & $22.2 b$ & $16.6 a$ & $23.2 b$ \\
\hline $2,2^{\prime}, 3,3^{\prime}, 4,5,6,6^{\prime}-\mathrm{CB}$ & $0.91 \pm 0.001$ & $0.89 \pm 0.003$ & $8.3 a$ & $14.9 \mathrm{~b}$ & $12.6 \mathrm{C}$ & $16.2 \mathrm{C}$ \\
\hline $3,3^{\prime}, 4,4^{\prime}, 5,5^{\prime}-\mathrm{CB}$ & $0.11 \pm 0.000$ & $0.08 \pm 0.001$ & $26.1 \mathrm{a}$ & $25.9 a$ & $39.3 b$ & $26.6 \mathrm{a}$ \\
\hline $2,2^{\prime}, 3,3^{\prime}, 4,4^{\prime}, 5 / 2,3,3^{\prime}, 4,4^{\prime}, 5,6-C B$ & $14.21 \pm 0.029$ & $13.90 \pm 0.047$ & $15.6 \mathrm{a}$ & $21.0 \mathrm{~b}$ & $22.9 c$ & $22.7 c$ \\
\hline $2,2^{\prime}, 3,3^{\prime}, 4,5,5^{\prime}, 6-C B$ & $0.21 \pm 0.00$ & $0.21 \pm 0.001$ & $35.1 \mathrm{a}$ & $41.4 \mathrm{~b}$ & $42.3 b$ & $41.8 \mathrm{~b}$ \\
\hline $2,2^{\prime}, 3,3^{\prime}, 4,5,5^{\prime}, 6+2,2^{\prime}, 3,3^{\prime}, 4,5,5^{\prime}, 6^{\prime}$ & $2.82 \pm 0.003$ & $2.77 \pm 0.008$ & $13.1 \mathrm{a}$ & $19.1 b$ & $19.7 b$ & $22.8 \mathrm{c}$ \\
\hline $2,2^{\prime}, 3,4,4^{\prime}, 5,5^{\prime}, 6 / 2,2^{\prime}, 3,3^{\prime}, 4,4^{\prime}, 5^{\prime}, 6-C B$ & $3.82 \pm 0.002$ & $3.79 \pm 0.020$ & $12.8 \mathrm{a}$ & $19.5 b$ & $19.7 b$ & $23.1 c$ \\
\hline $2,3,3^{\prime}, 4,4^{\prime}, 5,5^{\prime}-\mathrm{CB}$ & $0.34 \pm 0.001$ & $0.34 \pm 0.000$ & $16.3 \mathrm{a}$ & $22.0 \mathrm{~b}$ & $24.1 \mathrm{c}$ & $24.6 c$ \\
\hline $2,2^{\prime}, 3,3^{\prime}, 4,5,5^{\prime}, 6,6^{\prime} / 2,2^{\prime}, 3,3^{\prime}, 4,4^{\prime}, 5,6-C B$ & $1.82 \pm 0.001$ & $1.79 \pm 0.005$ & $12.0 \mathrm{a}$ & $18.1 \mathrm{~b}$ & $20.0 \mathrm{~b}$ & $19.7 b$ \\
\hline $2,2^{\prime}, 3,3^{\prime}, 4,4^{\prime}, 5,6,6^{\prime}-\mathrm{CB}$ & $0.11 \pm 0.000$ & $0.11 \pm 0.000$ & $10.3 c$ & $13.2 \mathrm{~b}$ & $11.5 a$ & $14.8 \mathrm{C}$ \\
\hline $2,2^{\prime}, 3,3^{\prime}, 4,4^{\prime}, 5,5^{\prime}-C B$ & $2.97 \pm 0.005$ & $2.96 \pm 0.011$ & $13.0 \mathrm{a}$ & $19.8 \mathrm{~b}$ & $16.7 b$ & $21.9 c$ \\
\hline $2,3,3^{\prime}, 4,4^{\prime}, 5,5^{\prime}, 6-C B$ & $0.29 \pm 0.011$ & $0.26 \pm 0.000$ & $16.8 \mathrm{c}$ & $14.2 \mathrm{~b}$ & $21.3 d$ & $21.1 \mathrm{a}$ \\
\hline $2,2^{\prime}, 3,3^{\prime}, 4,4^{\prime}, 5,5^{\prime}, 6-C B$ & $0.93 \pm 0.052$ & $0.91 \pm 0.064$ & $0.0 \mathrm{a}$ & $0.0 a$ & $0.0 \mathrm{a}$ & $5.1 b$ \\
\hline Overall PCBs & $776.3 \pm 1.2$ & $733.9 \pm 2.3$ & 28.0 & 24.5 & 33.8 & 26.9 \\
\hline
\end{tabular}

Initial PCB congeners concentrations in maize stalk-amended soil in the absence (Soil as such) and in the presence of soybean oil (Soil with SO) and removals (\%) in the respective controls (i.e, ICM and ICSOM) and in the Lentinus tigrinus-augmented microcosms ( $L t \mathrm{M}$ and $L t S O M)$ after $60 \mathrm{~d}$ at $28^{\circ} \mathrm{C}$.

tData are mean \pm standard deviation of two independent experiments; ${ }^{*}$ Multiple pairwise comparisons were performed between row means $(\mathrm{P} \leq 0.05)$;

lowercase letters indicate absence of statistically significant differences.

PCB dechlorination had occurred after $60 \mathrm{~d}$ incubation. The inset in Figure 6 shows that PROCBC was higher than $15 \%$ in all microcosms and that best dechlorination was observed in $\operatorname{LtM}$ (i.e., $23.2 \pm 1.3 \%$ ) in agreement with the previously mentioned best depletion performances of this microcosm. With regard to the ability of WRB to perform PCB dechlorination, an oxidative chloride removal at the para-position was reported for two penta-CBs [11]. In addition, WRB and extracellular oxidases thereof produced, such as laccases, are able to bring about the oxidative dehalogenation of hydroxylated PCBs $[10,11]$. These intermediates, generated by both the aerobic biphenyl pathway and the intracellular fungal monooxygenases [3], are thus susceptible to oxidation by laccase, the presence of which was mostly detected in $L t \mathrm{M}$ and, to a lesser extent, in $L t \mathrm{SOM}$.

The higher contaminant depletion in LtM than in the corresponding incubation control, significant for the majority of PCB homologues, could be due to a significant contribution of the fungus in the degradation process. This can be inferred by the lower densities of cultivable BDB in LtM than ICM and by the timedependent decrease in $b p h$ abundances in the former. Moreover, in addition to the reported capability of $L$. tigrinus to degrade PCBs [4], our strain was found to be able to deplete and detoxify chlorobenzoates [22]. However, the absence in $L t \mathrm{M}$ of an evident double-para recalcitrance effect, related to the resistance of 4,4'chloro-substituted congeners to fungal degradation and commonly reported for several fungi $[5,9,12,33]$, might suggest that the higher performances of this microcosm than ICM might be ascribed to a cooperative effect of $L$. tigrinus with the resident microbiota. Such a cooperation might involve its above reported degradation ability of CBAs which are known to exert a significant inhibitory action towards biphenyl-degrading bacteria [35]. In 


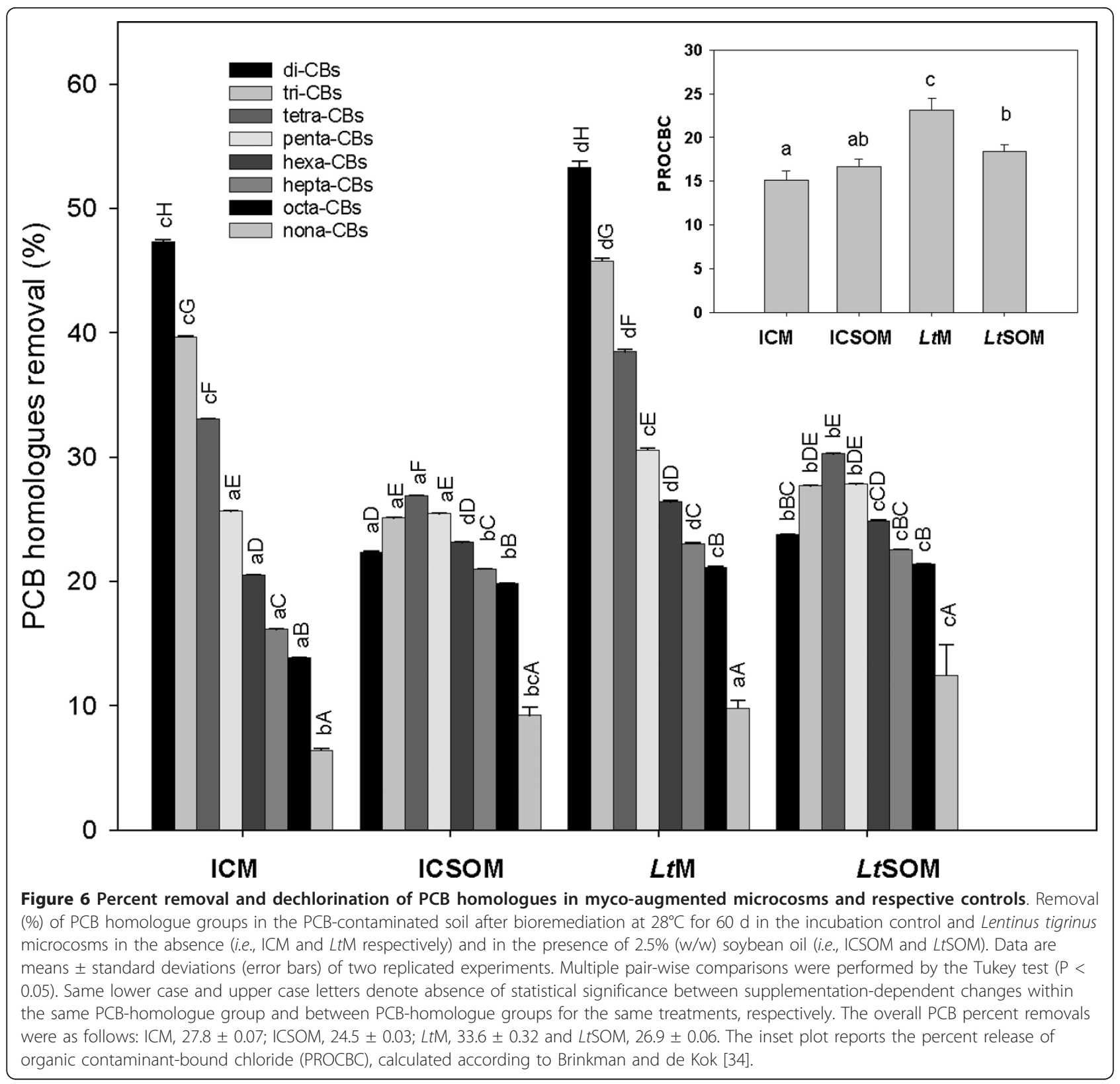

addition, the hyphal network of fungi is known to act as a dispersion vector of specialized bacteria, the movement of which is severely limited by the discontinuity of the water paths under unsaturated solid phase conditions [36,37]. An additional indirect contribution of the fungus to the degradation process might stem from its ability to produce EGH activities in soil, the organic matter content of which was far from being negligible. With this regard, hydrolytic exoenzymes significantly contribute to the mobilization of PCBs from soil, by either shifting the sorption equilibrium in the course of soil organic matter (SOM) transformation into dissolved organic matter or by facilitating contaminant diffusion via the hydrolase-promoted reduction in rigidity of SOM [38].

With regard to the effect of $\mathrm{SO}$, its presence negatively affected the depletion of low chlorinated congeners, regardless of the use of bioaugmentation. Explanations pertaining to the failure of $\mathrm{SO}$ in enhancing PCB removals might be derived from other studies showing that, although MAs promoted PCB pseudosolubilization, their use led to decreased degradation rates either due to desorption of degrading microorganisms from the matrix or to surfactant-promoted changes in community composition with a decrease in degrader populations $[39,40]$. The latter hypothesis seems to be 
supported by our data since this additive exerted a depressive effect on the abundances of $b p h$ of the upper PCB degradation pathway and on cultivable biphenyldegrading bacteria in incubation controls. Conversely, the higher depletions of hexa- up to octa-CBs in ICSOM than in ICM cannot be ascribed to the action of aerobic bacteria, that have been shown to be scarcely competent on these high chlorinated congeners. To explain these findings, possible occurrence of anaerobic micro-niches induced by the persistence of SO might not be ruled out. This additive, in fact, is commonly used in field-scale remediation of soils contaminated with chlorinated aliphatic compounds to provide a reactive bio-barrier and to sustain anaerobic dechlorination [41].

\section{Conclusions}

L. tigrinus was able to efficiently colonize the heavily and historically contaminated soil leading to an enhancement of the biodiversity of the resident microbiota albeit with a depressive effect on biphenyl-degrading bacteria. However, fungal augmentation led to PCB removal extents (about 34\%) after $60 \mathrm{~d}$ incubation which were by far higher than other remediation studies conducted under unsaturated solid phase conditions on actual site soils contaminated by Aroclor 1260 $[19,29,30]$. Although MMS was used as an inoculum carrier or segregated layer in augmented and incubation control microcosms, respectively, its presence proved to be a key factor since in the latter ones a relevantly higher overall PCB depletion than that achieved with a biostimulation treatment of the same soil with biphenyl $\left(4 \mathrm{~g} \mathrm{~kg}^{-1}\right)$ in a solid-phase reactor $(27.8$ vs. $2.01 \%$, respectively) was observed [19]. The lack of significant effects on PCB recovery in the MMS-amended soil with respect to the non-amended one and the use of this additive in sterilized form ensure that its effects on degradation were not due to either artifacts in contaminant recovery or to the addition of amendant-associated exogenous microbiota, respectively. Regardless of the augmentation, the addition of SO negatively affected the depletion of low chlorinated congeners and thus its use might not be advisable in soils contaminated by technical PCB mixtures such as Aroclor 1242 and Delor 103.

\section{Methods \\ Materials}

The historically Aroclor 1260-contaminated soil, kindly supplied by Area SpA (Ravenna, Italy), was homogenized, air-dried, passed through a $2 \mathrm{~mm}$-sieve and then stored at $4^{\circ} \mathrm{C}$ until used. Its main properties were as follows: real and potential acidity, 7.0 and 6.4 , respectively; WHC, 25.7\%; total phosphorous, $0.82 \%$; total organic carbon, $2.1 \%$; total organic matter, 3.6\%; total nitrogen,
$1.2 \%$; sand, $88 \%$; silt, $11 \%$; clay $1 \%$. Both identity and initial concentrations of PCB congeners in incubation control microcosms (please, see below) are reported in Table 1.

\section{Microorganism and inoculum preparation}

Lentinus tigrinus CBS 577.79 was maintained at $28^{\circ} \mathrm{C}$ on potato-dextrose agar (PDA) and sub-cultured every month. Mycelial fragments from 10-d-old PDA-slant cultures were suspended in $5 \mathrm{ml}$ of sterile deionized water and used as inocula for liquid pre-cultures in 500$\mathrm{ml}$ Erlenmeyer flasks containing $95 \mathrm{ml}$ of the following medium $\left(\mathrm{g} \mathrm{l}^{-1}\right)$ : glucose, 10; yeast extract (Oxoid, Basingstoke, UK), 5. After $96 \mathrm{~h}$ incubation at $28^{\circ} \mathrm{C}$ under orbital shaking $(180 \mathrm{rpm})$, the pre-cultures were centrifuged $(4,000 \times \mathrm{g}, 10 \mathrm{~min})$ and washed with deionized water. The mycelium was homogenized by Ultra-Turrax (IKA Labortechnik, Staufen, Germany) and added with deionized water to yield a biomass concentration of $10 \mathrm{~g} \mathrm{l}^{-1}$ which was then used as the inoculum. Milled maize stalks (MMS), the moisture content of which was adjusted to 75\%, were placed in 1-1 Pyrex bottles covered with Teflon lined stoppers, sterilized in autoclave $\left(121^{\circ} \mathrm{C}, 30 \mathrm{~min}\right)$ and, after cooling, added with $2.0 \mathrm{ml}$ fungal inoculum. Fungal cultures were incubated at $28^{\circ}$ $\mathrm{C}$ for $7 \mathrm{~d}$ under stationary conditions.

\section{Microcosms preparation}

Regardless of the presence of the additive, the PCB-contaminated soil $(30 \mathrm{~g})$ was invariably adjusted to a moisture content equal to $65 \%$ of its WHC and added over either sterile $\left(120^{\circ} \mathrm{C}, 30 \mathrm{~min}\right)$ non-inoculated MMS or the same fungal-overgrown substrate ( $7.5 \mathrm{~g}$ dry mass) to yield, respectively, the incubation control and L. tigrinus microcosms (ICM and $L t \mathrm{M}$, respectively). To prepare the soybean-amended incubation control and L. tigrinus microcosms (ICSOM and $L t$ SOM), soil (30 g) underwent nebulization with a previously sterilized $\left(121^{\circ} \mathrm{C}\right.$ for $15 \mathrm{~min})$ oil-water emulsion $(1: 1, \mathrm{w} / \mathrm{w})$ to reach an oil concentration of $2.5 \%(\mathrm{w} / \mathrm{w})$ and then layered over either sterile $\left(120^{\circ} \mathrm{C}, 30 \mathrm{~min}\right)$ non-inoculated MMS or fungal-overgrown substrate ( $7.5 \mathrm{~g}$ dry mass). All experiments were conducted in duplicate at $28^{\circ} \mathrm{C}$ for 30 and $60 \mathrm{~d}$ in 1-1 Pyrex bottles covered with Teflon lined stoppers under stationary conditions.

\section{Extraction of PCBs and analytical procedures}

PCBs were extracted from the soil-phase by using a hexane:acetone $(1: 1, \mathrm{v} / \mathrm{v})$ mixture in a Pressurized Fluid Extraction system (Dionex Corporation, Sunnyvale, CA, USA) operating at $140 \mathrm{~atm}$ and $100^{\circ} \mathrm{C}$ according to the procedure US-EPA-SW-846, Method 3545A. Both qualitative and quantitative $\mathrm{PCB}$ analyses were performed with a gas chromatograph (5890 series II), equipped 
with a HP-5 capillary column (30 $\mathrm{m}$ by $0.25 \mathrm{~mm}$ ) and an electron capture detector (Hewlett-Packard, Palo Alto, CA) as previously described [42]. The depletion of each congener was calculated from the mean of two chromatographic runs. On an average basis, percent residual standard deviation in the quantitation of congeners amounted to $0.24 \%$. Overall degradation activities in each microcosm were determined by both the total weight of residual PCBs obtained by summing the concentrations of each congener and by the summation of contaminants with the same extent of chlorination (homologues). To determine chloride ion contents in incubation controls and bioaugmented microcosms, specimens were added with double distilled water to yield a $20 \%(\mathrm{w} / \mathrm{v})$ slurry and orbitally shaken $(200 \mathrm{rpm})$ for $2 \mathrm{~d}$ at $20^{\circ} \mathrm{C}$. Then, the resulting suspensions were centrifuged $(11,000 \mathrm{~g}, 15 \mathrm{~min})$ and the supernatants passed through $0.45 \mu \mathrm{m}$ Minisart syringe filters (Sartorius, Göttingen Germany). The filtrates were then analyzed according to the method of Florrence and Farrar [43]. To determine the percent release of organic contaminant-bound chloride (PROCBC), the differences between chloride contents after $60 \mathrm{~d}$ incubation and at start in each microcosm were related to the theoretical PCBbound chloride calculated according to Brinkman and de Kok [34].

\section{Bacterial enumeration, mycelial growth and biochemical assays}

The concentration of the aerobic heterotrophic cultivable bacterial biomass and that of the biphenyl- or CBAgrowing aerobic cultivable bacteria was determined by the plate counting technique described by Fava and Di Gioia [18]. Extraction and subsequent HPLC determination of ergosterol, as a specific index of fungal biomass, were carried out as already reported [23]. Enzymes were extracted from soil samples and subsequently assayed as previously reported [8]. EGH (i.e., endo- $\beta$-1,4-glucanase, cellobiohydrolase and endo- $\beta-1,4$-xylanase), EPO (i.e, laccase and Mn-dependent peroxidase) and dehydrogenase activities were determined as reported by Leonardi et al. [8]. All activities were expressed in milli-International Units (mIU), defined as the amount of enzyme producing $1 \mathrm{nmol}$ of product per minute under the assay conditions.

\section{DNA extraction, PCR amplification and DGGE analyses}

Total community DNA was extracted from soil (250 mg) using the Power Soil DNA Extraction Kit (MoBio Laboratories, Carlsbad, CA) following the manufacturer's instruction. Variable regions of $16 \mathrm{~S}$ and $18 \mathrm{~S}$ rRNA genes were amplified separately from $10 \mathrm{ng}$ of DNA in a PCR reaction with 0.4 and $0.8 \mu \mathrm{M}$ of the primers reported by Muyzer et al. [44] and Das et al. [45], respectively, using the illustra ${ }^{\mathrm{TM}}$ HotStart Master Mix (GE Healthcare, Little Chalfont UK). PCR amplification was performed in a thermal cycler (Bio-Rad Laboratories, Hercules, CA) as previously reported [28]. PCR products from 3 parallel amplifications were pooled, concentrated with a Microcon filter (Millipore, Bedford, MA), separated in $1.5 \%(\mathrm{w} / \mathrm{v})$ agarose gel and then stained with ethidium bromide.

The INGENYphorU-2 system for DGGE (Ingeny International BV, Goes, NL) was used. Protocol of analysis and estimation of microbial diversity indices (i.e., richness, $S$; Shannon-Weaver index, $H$ ) for each sample were as already reported [28]. An unweighed pair group method with arithmetic means (UPGMA) dendrogram was generated from a similarity matrix based on common band positions between lanes and calculated using the Dice's coefficient [46].

\section{Quantitative real-time PCR assays}

Quantitative real-time PCR (qPCR) was performed on an iCycler IQ (BioRad, Hercules, CA) using the SYBR Green JumpStart ${ }^{\mathrm{TM}}$ Taq ReadyMix ${ }^{\mathrm{TM}}$ (Sigma, Milan, Italy) following the manufacturer's instruction. The amplification of $16 \mathrm{~S}$ rRNA genes was performed with $0.05 \mu \mathrm{M}$ and $0.9 \mu \mathrm{M}$ of primers $341 \mathrm{~F}$ and 534R [44], respectively. The biphenyl dioxygenase (bph) and catechol 2,3-dioxygenase (C230) catabolic genes were amplified using $0.4 \mu \mathrm{M}$ each of primers BPHF3 and BPHR3 [47] and $0.2 \mu \mathrm{M}$ each of primers C230F and C230R [48], respectively. Amplification was carried out in a total volume of $25 \mu \mathrm{l}$ containing $12.5 \mu \mathrm{l}$ of $2 \mathrm{x}$ SYBR Green JumpStart Taq mix, $2.5 \mu \mathrm{l}$ of each primer and 7.5 $\mu \mathrm{l}$ of template DNA. To avoid PCR amplification problems due to the presence of inhibitors, dilution of environmental DNA samples ranged from 10 to 100 times.

The amplifications were carried out with a first step of $95^{\circ} \mathrm{C}$ ( $5 \mathrm{~min}$ ), followed by 50 cycles of $30 \mathrm{~s}$ of denaturation at $95^{\circ} \mathrm{C}, 30 \mathrm{~s}$ at 55,60 , and $57^{\circ} \mathrm{C}$, for the $16 \mathrm{~S}$ rRNA, bph and $\mathrm{C} 230$ genes, respectively, and $30 \mathrm{~s}$ of elongation at $72^{\circ} \mathrm{C}$. The final step consisted of $7 \mathrm{~min}$ at $72^{\circ} \mathrm{C}$. At the end of the qPCR a melting curve analysis was performed by measuring the SYBR Green I signal intensities during a $0.5^{\circ} \mathrm{C}$ temperature increment every $10 \mathrm{~s}$ from $50^{\circ} \mathrm{C}$ to $95^{\circ} \mathrm{C}$. Abundances of target genes in the microcosms investigated were expressed as changes (fold) with respect to their relative zero-timepoint, according to the expression:

$$
\text { Fold }=2^{(C t x)-(C t o)}
$$

where Cto and Ctx are the threshold cycles for the zero and successive time-points, respectively. The threshold cycle $(\mathrm{Ct})$ is the cycle number at which the 
fluorescence generated within a reaction crosses the threshold. The specificity of the qPCR assays was confirmed by the occurrence of both single melting peaks and unique bands of the expected size on agarose gels.

\begin{abstract}
Abbreviations
BDB: biphenyl-degrading bacteria; Bph: biphenyl dioxygenase; CBA: chlorobenzoic acids; C230: catechol-2,3-dioxygenase; DGGE: denaturing gradient gel electrophoresis; EGH: extracellular glycosyl hydrolases; $\mathrm{H}$ : Shannon-Weaver index; ICM: incubation control microcosm; ICSOM: incubation control microcosm with soybean oil; EPO: extracellular phenoloxidases; LtM: Lentinus tigrinus microcosm; LtSOM: Lentinus tigrinus microcosm with soybean oil; MAs: mobilizing agents; MMS: milled maize stalks; PCBs: polychlorobiphenyls; PROCBC: percent release of organic contaminant-bound chloride; QPCR: quantitative real-time polymerase chain reaction; S: richness; SO: soybean oil; SOM: soil organic matter; WHC: waterholding capacity; WRB: white-rot basidiomycetes.
\end{abstract}

\section{Acknowledgements}

We thank the Ministero dell'Istruzione dell'Università e della Ricerca (MIUR) that supported this work within the project 2008P7K379.

\section{Author details}

'Department of Cellular and Environmental Biology, University of Perugia, Perugia, Italy. ${ }^{2}$ Department for Innovation in Biological, Agro-Food and Forest Systems, University of Tuscia, Viterbo, Italy. ${ }^{3}$ Department of Civil, Environmental and Materials Engineering, Unit of Environmental Biotechnology and Biorefinery, Alma Mater Studiorum, University of Bologna, Bologna, Italy.

\section{Authors' contributions}

$F E, G Z, F F, M P$ and $A D$ have equally contributed to the conception of the experimental design, interpretation of data and to the preparation of the current version of this submission. MG, AN and GS contributed to data acquisition and analysis and have been actively involved in drafting the manuscript and in the approval of its current version. All authors read and approved the final manuscript.

\section{Competing interests}

The authors declare that they have no competing interests.

Received: 4 January 2012 Accepted: 23 March 2012

Published: 23 March 2012

\section{References}

1. Beyer A, Biziuk M: Environmental fate and global distribution of polychlorinated biphenyls. Rev Environ Contam Toxicol 2009, 201:137-158.

2. Pieper DH: Aerobic degradation of polychlorinated biphenyls. Appl Microbiol Biotechnol 2005, 67:170-191.

3. Field JA, Sierra-Alvarez R: Microbial transformation and degradation of polychlorinated biphenyls. Environ Pollut 2008, 155:1-12.

4. Šašek V, Volfova O, Erbanova P, Vyas BRM, Matucha M: Degradation of PCBs by white rot fungi, methylotrophic and hydrocarbon utilizing yeasts and bacteria. Biotechnol Lett 1993, 15:521-526.

5. Kubátová A, Erbanová P, Eichlerová I, Homolka L, Šašek V: PCB congener selective biodegradation by the white rot fungus Pleurotus ostreatus in contaminated soils. Chemosphere 2001, 43:207-215.

6. Ohtsubo Y, Kudo T, Tsuda M, Nagata Y: Strategies for bioremediation of polychlorinated biphenyls. Appl Microbiol Biotechnol 2004, 65:250-258.

7. Yadav JS, Quensen JF, Tiedje JM, Reddy CA: Degradation of polychlorinated biphenyl mixtures (Aroclors 1242, 1254, and 1260) by the white rot fungus Phanerochaete chrysosporium as evidenced by congener-specific analysis. Appl Environ Microbiol 1995, 61:2560-2565.

8. Leonardi V, Giubilei MA, Federici E, Spaccapelo R, Šašek V, Novotny C, Petruccioli M, D'Annibale A: Mobilizing agents enhance fungal degradation of polycyclic aromatic hydrocarbons and affect diversity of indigenous bacteria in soil. Biotechnol Bioeng 2008, 101:273-285.

9. Beaudette LA, Davies S, Fedorak PM, Ward OP, Pickard MA: Comparison of gas chromatography and mineralization experiments for measuring loss of selected polychlorinated biphenyl congeners in cultures of white rot fungi. Appl Environ Microbiol 1998, 64:2020-2025.

10. Keum YS, Li QX: Fungal laccase-catalyzed degradation of hydroxy polychlorinated biphenyls. Chemosphere 2004, 56:23-30.

11. Kamei I, Sonoki S, Haraguchi K, Kondo R: Fungal bioconversion of toxic polychlorinated biphenyls by white-rot fungus Phlebia brevispora. Appl Microbiol Biotechnol 2006, 73:932-940.

12. Zeddel A, Majcherczyk A, Hüttermann A: Degradation of polychlorinated biphenyls by white-rot fungi Pleurotus ostreatusand Trametes versicolorin a solid state system. Toxicol Environ Chem 1993, 40:255-266.

13. Donnelly KP, Hegde SR, Fletcher SH: Growth of PCB-degrading bacteria on compounds from photosynthetic plants. Chemosphere 1994, 28:981-988.

14. Bruce W, Folkerts O, Garnaat C, Crasta O, Roth B, Bowena B: Expression profiling of the maize flavonoid pathway genes controlled by estradiolinducible transcription factors CRC and P. The Plant Cell 2000, 12:65-79.

15. Köllner TG, Schnee C, Gershenzon J, Degenhardt J: The sesquiterpene hydrocarbons of maize (Zea mays) form five groups with distinct developmental and organ-specific distributions. Phytochemistry 2004, 65:1895-1902.

16. Bezama A, Navia R, Mendoza G, Barra R: Remediation technologies for organochlorine-contaminated sites in developing countries. Rev Environ Contam Toxicol 2008, 193:1-29.

17. Billingsley KA, Backus SM, Ward OP: Effect of surfactant solubilization on biodegradation of polychlorinated biphenyl congeners by PseudomonasLB400. Appl Microbiol Biotechnol 1999, 52:255-260.

18. Fava F, Di Gioia D: Soya lecithin effects on the aerobic biodegradation of polychlorinated biphenyls in an artificially-contaminated soil. Biotechnol Bioeng 2001, 72:177-184.

19. Fava F, Bertin L, Fedi A, Zannoni D: Methyl- $\beta$-cyclodextrin-enhanced solubilization and aerobic biodegradation of polychlorinated biphenyls in two aged-contaminated soils. Biotechnol Bioeng 2003, 81:381-390.

20. Pizzul L, del Pilar Castillo M, Stenström J: Effect of rapeseed oil on the degradation of polycyclic aromatic hydrocarbons in soil by Rhodococcus wratislaviensis. Int Biodeterior Biodegr 2007, 59:111-118.

21. Yap CL, Gan S, Ng HK: Application of vegetable oils in the treatment of polycyclic aromatic hydrocarbons-contaminated soils. J Hazard Mat 2010, 177:28-41.

22. Covino S: In vivo and in vitro degradation of aromatic contaminants by white rot fungi. A case study: Panus tigrinus CBS 577.79. PhD thesis University of Tuscia, Agrobiology and Agrochemistry Department; 2010 [http://hdl.handle.net/2067/1200].

23. Giubilei MA, Leonardi V, Federici E, Covino S, Šašek V, Novotny C, Federici F, D'Annibale A, Petruccioli M: Effect of mobilizing agents on mycoremediation and impact on the indigenous microbiota. J Chem Technol Biotechnol 2009, 84:836-844.

24. Dyakov MY, Kamzolkina OV, Shtaer OV, Bis'ko NA, Poedinok NL, Mikhailova OB, Tikhonova OV, Tolstikhina TE, Vasil'eva BF, Efremenkova OV: Morphological characteristics of natural strains of certain species of basidiomycetes and biological analysis of antimicrobial activity under submerged cultural conditions. Microbiology 2011, 80:274-285.

25. Hirasawa M, Shouji N, Neta T, Fukushima K, Takada K: Three kinds of antibacterial substances from Lentinus edodes (Berk.) Sing. (Shiitake, an edible mushroom). Int J Antimicrob Agents 1999, 11:151-157.

26. Ford Cl, Walter M, Northcott GL, Di HJ, Cameron KC, Trower T: Fungal inoculum properties: extracellular enzyme expression and pentachlorophenol removal in highly contaminated field soils. J Environ Qual 2007, 36:1599-1608.

27. Leštan $D$, Leštan $M$, Chapelle JA, Lamar RT: Biological potential of fungal inocula for bioaugmentation of contaminated soils. J Ind Microbiol 1996, 16:286-294.

28. Federici E, Giubilei MA, Cajthaml T, Petruccioli M, D'Annibale A: Lentinus (Panus) tigrinus augmentation of a historically contaminated soil: matrix decontamination and structure and function of the resident bacterial community. J Hazard Mat 2011, 186:1263-1270.

29. Di Toro S, Zanaroli G, Fava F: Intensification of the aerobic bioremediation of an actual site soil historically contaminated by polychlorinated biphenyls (PCBs) through bioagumentation with non acclimated, complex source of microorganisms. Microb Cell Fact 2006, 5:11.

30. Tigini V, Prigione V, Di Toro S, Fava F, Varese GC: Isolation and characterization of polychlorinated biphenyl (PCB) degrading fungi from a historically contaminated soil. Microb Cell Fact 2009, 8:5. 
31. Dawson JC, Godsiffe EJ, Thompson IP, Ralebitso-Senior TK, Killham KS, Paton GI: Application of biological indicators to assess recovery of hydrocarbon impacted soils. Soil Biol Biochem 2007, 39:164-177.

32. Giovannozzi Sermanni G, D'Annibale A, Di Lena G, Vitale NS, Di Mattia E, Minelli V: The production of exo-enzymes of Lentinus edodes and Pleurotus ostreatus and their use for upgrading corn straw. Bioresour Technol 1994, 48:173-178.

33. Moeder M, Cajthaml T, Koeller G, Erbanová P, Šašek V: Structure selectivity in degradation and translocation of polychlorinated biphenyls (Delor 103) with a Pleurotus ostreatus culture. Chemosphere 2005, 61:1370-1378.

34. Brinkman UAT, de Kok A: Halogenated biphenyls, triphenyl, naphthalenes, dibenzodioxins and related products. In Production, properties and usage. Edited by: Kimbroug RB. Amsterdam: Elsevier/North Holland Biomedical Press; 1980:1-40.

35. Stratford J, Wright MA, Reineke W, Mokross H, Havel J, Knowles CJ, Robinson GK: Influence of chlorobenzoates on the utilisation of chlorobiphenyls and chlorobenzoate mixtures by chlorobiphenyl/ chlorobenzoate-mineralising hybrid bacterial strains. Arch Microbiol 1996, 165:213-218.

36. Kohlmeier S, Smits TH, Ford RM, Keel C, Harms H, Wick LY: Taking the fungal highway: mobilization of pollutant-degrading bacteria by fungi. Environ Sci Technol 2005, 39:4640-4646.

37. Furuno S, Päzolt K, Rabe C, Neu TR, Harms H, Wick LY: Fungal mycelia allow chemotactic dispersal of polycyclic aromatic hydrocarbondegrading bacteria in water-unsaturated systems. Environ Microbiol 2010, 12:1391-1398.

38. Wicke D, Reemtsma T: Mobilization of hydrophobic contaminants from soils by enzymatic depolymerization of soil organic matter. Chemosphere 2011, 78:996-1003.

39. Stelmack PL, Gray MR, Pickard MA: Bacterial adhesion to soil contaminants in the presence of surfactants. Appl Environ Microbiol 1999, 65:163-168.

40. Colores GM, Macur RE, Ward DM, Inskeep WP: Molecular analysis of surfactant-driven microbial population shifts in hydrocarbon contaminated soil. Appl Environ Microbiol 2000, 66:2959-2964.

41. Borden RC: Effective distribution of emulsified edible oil for enhanced anaerobic bioremediation. J Contam Hydrol 2007, 194:1-12.

42. Fava F, Di Gioia D, Marchetti L: Cyclodextrin effects on the ex situ bioremediation of a chronically polychlorinated biphenyl-contaminated soil. Biotechnol Bioeng 1998, 58:345-355.

43. Florrence TM, Farrar YJ: Spectrophotometric determination of chloride at the part per billion level by the mercury(II) thiocyanante method. Anal Chim Acta 1971, 54:373-377.

44. Muyzer G, de Waal EC, Uitterlinden AG: Profiling of complex microbial populations by denaturing gradient gel electrophoresis analysis of polymerase chain reaction-amplified genes coding for $16 \mathrm{~S}$ rRNA. Appl Environ Microbiol 1993, 59:695-700.

45. Das M, Royer TV, Leff LG: Diversity of fungi, bacteria and actinomycetes on leaves decomposing in a stream. Appl Environ Microbiol 2007, 73:756-767.

46. Li C, Moe WM: Assessment of microbial populations in methyl ethyl ketone degrading biofilters by denaturing gradient gel electrophoresis. Appl Microbiol Biotechnol 2004, 64:568-575.

47. Baldwin BR, Nakatsu CH, Nies L: Detection and enumeration of aromatic oxygenase genes by multiplex and real-time PCR. Appl Environ Microbiol 2003, 69:3350-3358.

48. Sei K, Asano K, Tateishi N, Mori K, Ike M, Fujita M: Design of PCR primers and gene probes for the general detection of bacterial populations capable of degrading aromatic compounds via catechol cleavage pathways. J Biosci Bioeng 1999, 88:542-550.

doi:10.1186/1475-2859-11-35

Cite this article as: Federici et al:: Bioaugmentation of a historically contaminated soil by polychlorinated biphenyls with Lentinus tigrinus. Microbial Cell Factories 2012 11:35.

\section{Submit your next manuscript to BioMed Central and take full advantage of:}

- Convenient online submission

- Thorough peer review

- No space constraints or color figure charges

- Immediate publication on acceptance

- Inclusion in PubMed, CAS, Scopus and Google Scholar

- Research which is freely available for redistribution

Submit your manuscript at www.biomedcentral.com/submit
C Biomed Central 